\title{
A Formação Continuada de Professores na perspectiva dos Conhecimentos Didáticos Matemáticos
}

\author{
Patrícia Pujol Goulart Carpes \\ Eleni Bisognin
}

\begin{abstract}
Resumo: O presente estudo visa identificar e analisar as possíveis contribuições do sistema modular Conhecimentos Didáticos Matemáticos (CDM) em um curso formativo e investigativo com professores de Matemática. Para tal, organizou-se um curso na perspectiva do CDM para o ensino de números racionais no Ensino Fundamental. A pesquisa, de base qualitativa, teve seus dados analisados a partir do Guia de Avaliação da Idoneidade Didática de Processos de Instrução em Educação Matemática. Esse guia fornece componentes e indicadores para analisar e avaliar cursos de formação de professores por meio das dimensões do CDM. As atividades do curso foram construídas, desenvolvidas e registradas por meio de portfólios individuais e socializadas entre o grupo. Ao analisalos aponta-se que serviram para orientar e organizar as atividades além de propiciar a reflexão sobre os conhecimentos mobilizados, principalmente epistêmicos e cognitivos.
\end{abstract}

Palavras-chave: Ensino e aprendizagem dos números racionais. Enfoque Ontossemiótico do Conhecimento e da Instrução Matemática. Educação Básica.

\section{The Continuing Training of Teachers from the Perspective of Mathematical Didactic Knowledge}

\begin{abstract}
This study aims to identify and analyze the possible contributions of the modular system Mathematical Didactic Knowledge (MDK) in a course with Mathematics teachers. Therefore, a course was organized in the perspective of the MDK for the teaching of rational numbers at Elementary School level. The research, of qualitative basis, had its data analyzed from the Guide of Evaluation of Didactic Suitability of Instruction Processes in Mathematical Education. This guide provides components and indicators to analyze and evaluate teacher training

Patricia Pujol Goulart Carpes Doutor em Ensino Ciências e Matemática pela Universidade Franciscana. Professora da Universidade Federal do Pampa (UNIPAMPA), Itaqui, RS, Brasil. iD http://orcid.org/0000-0001-5206-8718 courses through the dimensions of the MDK. The activities of the course were built, developed and registered through individual portfolios and socialized among the group. When analyzing them, it is pointed out that they served to guide and organize the their activities in addition to providing reflection about the knowledge mobilized, mainly epistemic and cognitive.
\end{abstract} $\triangle$ patriciacarpes@unipampa.edu.br

Eleni Bisognin Universidade Federal do Rio de Janeiro.

Professor da Universidade Franciscana

(UFN), Santa Maria, RS, Brasil.

http://orcid.org/0000-0003-3266-6336 $\checkmark$ eleni@ufn.edu.br

Recebido em 21/05/2021 Aceito em 19/06/2021 Publicado em 23/06/2021 Doutora em Matemática pela

Keywords: Teaching and learning of rational numbers. Ontosemiotic Approach to Knowledge and Mathematical Instruction. Basic Education.

\section{La formación continuada del profesorado desde la perspectiva del Conocimiento Didáctico Matemático}

Resumen: El presente estudio tiene como objetivo identificar y analizar los posibles aportes del sistema modular de Conocimiento Didáctico Matemático (CDM) en un curso formativo e investigativo con profesores de Matemática. Para esto, se organizó un curso desde la perspectiva del CDM para la enseñanza de los números racionales en la Enseñanza Fundamental. La investigación, con base cualitativa, tuvo sus datos analizados con base en la Guía de Evaluación de Idoneidad Didáctica para Procesos Instruccionales en Educación Matemática. Este guía proporciona componentes e indicadores para analizar y evaluar los cursos de formación docente a través de las dimensiones del CDM. Las actividades del curso se construyeron, desarrollaron y registraron a través de portafolios individuales y socializados entre el grupo. Al analizarlos, se señala que sirvieron para orientar y organizar actividades además de promover la reflexión sobre el conocimiento movilizado, principalmente epistémico y cognitivo. 
Palabras clave: Enseñar y aprender números racionales. Enfoque Ontosemiótico del Conocimiento y la Instrucción Matemática. Educación Basica.

\section{Introdução}

O presente estudo tem origem na tese da primeira autora, Carpes (2019), que buscou investigar, com base no sistema modular dos Conhecimentos Didáticos Matemáticos (CDM) desenvolvido por PinoFan e Godino (2015), o desenvolvimento de conhecimentos didáticos matemáticos sobre números racionais junto a um grupo de professores de Matemática. Destaca-se que o CDM é oriundo do Enfoque Ontossemiótico do Conhecimento e Instrução Matemática (EOS), desenvolvido por Godino e colaboradores (GODINO; BATANERO, 1994; GODINO, 2002; GODINO; BATANERO; FONT, 2007; FONT; GODINO; GALLARDO, 2013).

A temática selecionada para abordar durante a formação de professores de Matemática: os números racionais no Ensino Fundamental, tem evidências na própria literatura, como um objeto de conhecimento que apresenta muitas dificuldades aos alunos no processo de aprendizagem. Essas dificuldades podem estar relacionadas à complexidade do tema, a pouca maturidade dos alunos, ao uso de recursos e métodos não adequados para o ensino, ou pelas diferentes contextualizações/significados e representações que o conjunto numérico propicia (BEHR et al., 1983; LAMON, 2006; MAGINA; CAMPOS, 2008, SILVA, 2005). Além disso, os próprios professores participantes do curso indicaram a temática como necessária e com possíveis lacunas em suas formações.

A formação continuada de professores é amplamente reconhecida como necessária a fim de qualificar o processo de ensino e aprendizagem. Contudo, dificuldades recorrentes são encontradas nesse processo tais como a falta de tempo hábil para a participação e dedicação dos professores da Educação Básica ao curso de formação.

Além disso, depara-se com diferentes correntes da formação continuada de professores. Algumas preponderando a teoria, outras a prática, outras as trocas de experiências ou reflexões das práticas de ensino (BREDA; FONT; LIMA, 2005, IMBERNON, 2017, NÓVOA, 1992). Neste sentido, a escolha do sistema modular CDM para balizar o estudo tem duas vertentes de apoio, uma teórica e outra metodológica. Em outras palavras, por meio do CDM é possível identificar os conhecimentos matemáticos necessários para o ensino dos números racionais (em específico) obtendo assim o subsídio teórico do curso e, também, o como mobilizar tais conhecimentos pelos professores, por meio do Guia de Avaliação da Idoneidade Didática de Processos de Instrução em Educação Matemática no qual são destacados componentes e indicadores para análise. 
Diante desse contexto, o presente estudo visa identificar e analisar as possíveis contribuições do sistema modular, Conhecimentos Didáticos Matemáticos (CDM), em um curso formativo e investigativo com professores de Matemática da Educação Básica. Para tal, na sequência, apresentamse as dimensões do CDM, o percurso metodológico adotado para organizar, desenvolver e avaliar o curso de formação, bem como os principais resultados encontrados e as considerações finais.

\section{Os Conhecimentos Didáticos Matemáticos dos professores de Matemática}

Se hoje fazemos a pergunta "quais são os conhecimentos necessários ao professor no processo de ensino e aprendizagem?", diferentes respostas seriam apontadas. Buscando apoio científico para esta resposta, têm-se os estudos pioneiros de Shulman (1987, 1988), de Schoenfeld e Kilpatrick (2008), Ball, Thames e Phelps (2008), entre outros. Esses estudos categorizam os conhecimentos dos professores de forma global, porém, não permitem uma análise mais detalhada de cada um dos tipos de conhecimento empregados no ensino da Matemática (PINO-FAN; GODINO, 2015).

Em Pino-Fan e Godino (2015), os autores desenvolveram um sistema de categorias (ou dimensões) para analisar os conhecimentos dos professores de Matemática, denominado CDM. As categorias elaboradas estão relacionadas com os tipos de ferramentas teóricas de análise do EOS, em que se assume que cada ferramenta põe em jogo conhecimentos didáticos matemáticos.

O modelo CDM interpreta e organiza os conhecimentos do professor a partir de três dimensões, a saber: dimensão matemática, dimensão didática e dimensão meta didático-matemática. A figura 1 ilustra um esquema para o modelo CDM.

Figura 1: Dimensões e componentes do CDM

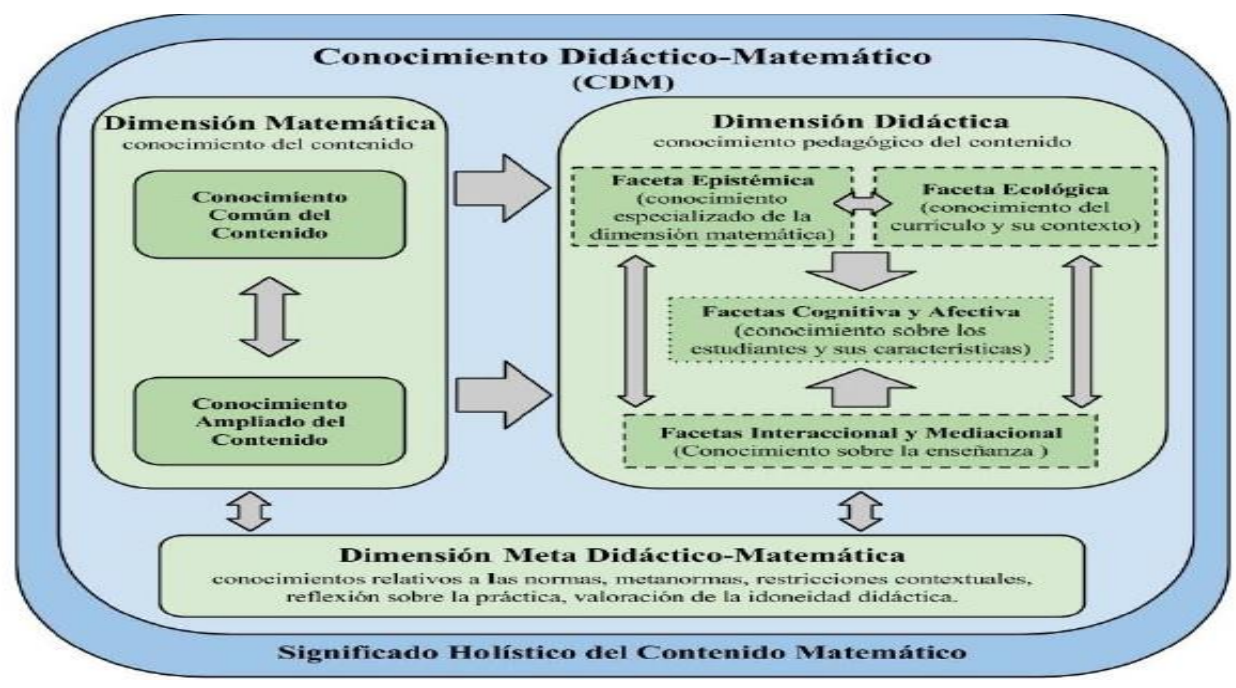

Fonte: Pino-Fan e Godino (2015, p. 98). 
A dimensão Matemática é composta por duas subdimensões: do conhecimento comum e do conhecimento ampliado, que atende a necessidade de solidificar os conhecimentos dos professores de Matemática em tópicos específicos de Matemática. Os autores entendem como conhecimento comum aquele conhecimento matemático compartilhado pelo professor e pelo aluno, isto é, o conhecimento suficiente para resolver um problema, por exemplo. O conhecimento ampliado é aquele que o professor deve ter sobre as noções matemáticas, saber vincular o objeto de estudo com outras noções matemáticas e encaminhar os alunos a estudos subsequentes (PINO-FAN; GODINO, 2015).

Compreende-se que o conhecimento matemático não é suficiente para o professor na sua prática de ensino e, sim, que o mesmo deve ter conhecimento de diversos fatores que interferem no planejamento e desenvolvimento de um conteúdo matemático. Neste contexto, é proposta a dimensão didática do CDM. A mesma é composta de seis facetas, a saber: faceta epistêmica (conhecimento especializado de Matemática), faceta cognitiva (conhecimento de aspectos cognitivos dos alunos), faceta afetiva (conhecimento dos aspectos afetivos, emocionais e atitudes dos estudantes), faceta interacional (conhecimento sobre interações presentes na sala de aula), faceta mediacional (conhecimento dos recursos e meios que potencializam a aprendizagem dos alunos) e a faceta ecológica (conhecimento sobre aspectos curriculares, sociais, políticos que influenciam na gestão da aprendizagem dos alunos).

A articulação de concepções envolvidas na faceta epistêmica compreende os conhecimentos da Matemática escolar com maior profundidade e amplitude (SCHOENFELD; KILPATRICK, 2008) como, também, o conhecimento especializado do conteúdo (BALL; THAMES; PHELPS, 2008). Deste modo, esta faceta leva em conta a ferramenta configuração ontossemiótica do EOS e indica que,

O professor deve ser capaz de mobilizar diversas representações de um objeto matemático, resolver a tarefa mediante distintos procedimentos, vincular o objeto matemático com outros objetos matemáticos de nível educativo no que se ensina ou de níveis anteriores ou posteriores, compreender e mobilizar a diversidade de significados parciais para um mesmo objeto matemático (que integram o significado holístico para este objeto), proporcionar diversas justificativas e argumentos, e identificar os conhecimentos postos em jogo durante a resolução de uma tarefa matemática. (PINO-FAN; GODINO, 2015, p. 99, tradução nossa)

As facetas cognitivas e afetivas estão relacionadas com a forma de pensar, conhecer ou atuar dos estudantes diante de um problema. A faceta cognitiva permite ao professor ajustar sua proposta ao grau de significados pessoais dos estudantes aos significados institucionais. E, ainda, nesta faceta, são considerados os conhecimentos que o professor deve ser capaz de realizar, tais como: perceber possíveis soluções a um problema dado a partir do seu planejamento ou execução da aula, concepções errôneas, dificuldades numa solução ou vínculo com o objeto matemático de estudo com outros conceitos. A dimensão afetiva versa sobre os conhecimentos que ajudam a descrever as experiências e sensações dos estudantes com um dado problema, por exemplo. 
A faceta interacional envolve os conhecimentos necessários para prever, desenvolver e avaliar sequências de interações entre os indivíduos para participarem do processo de ensino e aprendizagem, assim como orienta a negociação de significados aos estudantes. Essas interações podem ser professoraluno, aluno-aluno, professor-recurso, professor-aluno-recurso.

A faceta mediacional envolve os conhecimentos que o professor deve ter para avaliar a pertinência no uso de recursos didáticos para potencializar a aprendizagem, assim como o tempo destinado para tal procedimento.

A faceta ecológica refere-se aos conhecimentos de currículo de Matemática e relação com outros currículos, assim como, a relação do currículo com aspectos sociais, políticos e econômicos que condicionam o processo de ensino e aprendizagem.

Pino-Fan e Godino (2015) propõem as seis facetas da dimensão didática para poder analisar, descrever e desenvolver o conhecimento dos professores em diversas fases do processo de ensino e aprendizagem de tópicos de Matemática. Além disso, os professores necessitam como parte de seus conhecimentos didáticos matemáticos, conhecer e compreender os aspectos envolvidos em cada uma das fases da trajetória didática (estudo preliminar, planejamento, implementação e avaliação).

A dimensão meta didático-matemática é composta por duas partes: uma relativa aos conhecimentos sobre os critérios de idoneidade didática e a outra, se refere aos conhecimentos necessários para refletir sobre a própria prática (GODINO,2013). A idoneidade didática tem o caráter de avaliar o processo de ensino e aprendizagem, isto é, nela está presente a reflexão, a avaliação e a detecção das melhores potencialidades da prática. Segundo Schoenfeld e Kilpatrick (2008), a reflexão habitual da sua própria prática de ensino pode ser o principal mecanismo para melhorar a própria prática. O CDM prevê critérios de idoneidade que permitem ao professor realizar uma reflexão da sua prática. Esses critérios são determinados por meio do sistema EOS. Malet, Giacomene e Repeto (2021) apontam para a versatilidade da idoneidade didática como uma ferramenta teórica e metodológica, assim como uma competência específica do professor ao analisar e avaliar a idoneidade didática do processo desenvolvido.

Neste estudo, a análise dos resultados, balizado pelo Guia de Avaliação da Idoneidade Didática de Processos de Instrução em Educação Matemática (GODINO et al., 2013), tem ênfase na dimensão didática do CDM para melhor direcionar às contribuições do sistema modular durante a formação de professores. 


\section{Procedimentos metodológicos}

A metodologia de pesquisa escolhida segue uma abordagem qualitativa que, conforme Borba (2004) tem um entendimento dinâmico e está sendo empregado por diferentes linhas de pesquisa na área da Educação Matemática.

O que se convencionou chamar de pesquisa qualitativa prioriza procedimentos descritivos à medida que sua visão de conhecimento explicitamente admite a interferência subjetiva, o conhecimento como compreensão que é sempre contingente, negociada e não é verdade rígida. O que é considerado "verdadeiro", dentro desta concepção, é sempre dinâmico e passível de ser mudado. Isso não quer dizer que se deva ignorar qualquer dado do tipo quantitativo ou mesmo qualquer pesquisa que seja feita baseada em outra noção de conhecimento. (BORBA, 2004, p. 2)

Assim, essa pesquisa intenta descrever e analisar os fenômenos que ocorreram num processo de formação continuada de professores de Matemática de forma a contemplar as características, os valores, as dificuldades num viés qualitativo. Segundo Borba (2004), na pesquisa qualitativa o conhecimento está impregnado de valores, de intenção, história do pesquisador ou condições políticassociais, reconhecendo, dessa forma, que o investigador não é neutro nesta análise. Isto é, mantém contanto direto com o ambiente da pesquisa, com os sujeitos envolvidos e com os problemas de estudo propostos.

Os dados apontados são próprios dos sujeitos da pesquisa e do contexto sociocultural de que participam e que, via uma análise qualitativa, oportuniza sua compreensão e discussão. Nesta ótica, o pesquisador é passivel de apontar limitações e potencialidades na sua análise, assim como não possui um roteiro pré-determinado, rígido, a ser seguido.

\subsection{Local e sujeitos da pesquisa}

A pesquisa foi desenvolvida na Universidade Federal do Pampa (UNIPAMPA), no município de Itaqui, RS. Para tal, foi firmado um termo de cooperação e autorização entre a pesquisadora e a Secretaria de Educação de Itaqui. No instrumento foi acordado entre as partes que a pesquisadora ofertaria um curso de formação continuada aos professores de Matemática do Município e caberia à Secretaria de Educação do Município a disponibilização de carga horária dos docentes para formação. Assim, a Secretaria de Educação organizou que, no ano de 2018, todos os professores de Matemática, sujeitos da pesquisa, tivessem a carga horária destinada ao planejamento de atividades no mesmo dia, facilitando assim a participação dos docentes e a organização das escolas. Vale ressaltar que os professores participantes estavam cientes e de acordo com a proposta conforme Termo de Livre 
Consentimento e Anonimato, assim como a aprovação do projeto de tese pelo Comitê de Ética da Universidade.

\subsection{Instrumentos e procedimentos para coleta de dados}

O curso, organizado em nove encontros presenciais e sequenciais, com duração de quatro horas cada, explorou o objeto matemático números racionais. O Quadro 1 apresenta os temas e ações planejadas para cada encontro.

Quadro 1: Temas e ações desenvolvidos em cada encontro do Curso

\begin{tabular}{|c|c|c|}
\hline $\mathrm{N}^{0}$ & Temas & Ações planejadas \\
\hline 1 & $\begin{array}{l}\text { - Justificativa e estrutura do Curso. } \\
\text { - Dificuldades no processo de } \\
\text { ensino e aprendizagem. } \\
\text { - Os conhecimentos existentes dos } \\
\text { professores ao ensinar números } \\
\text { racionais. }\end{array}$ & $\begin{array}{l}\text { - Apresentar a proposta do Curso. } \\
\text { - llustrar algumas dificuldades de aprendizagem sobre números racionais } \\
\text { apresentadas na literatura. } \\
\text { - Levantar e discutir as dificuldades apresentadas no ambiente de sala de } \\
\text { aula dos próprios professores participantes, por meio de questionário. } \\
\text { - (Re)Conhecer os conhecimentos didáticos matemáticos dos professores } \\
\text { ao ensinar números racionais. }\end{array}$ \\
\hline 2 & $\begin{array}{l}\text { - Os significados dos números } \\
\text { racionais. } \\
\text { - Os conhecimentos existentes dos } \\
\text { professores ao ensinar números } \\
\text { racionais. }\end{array}$ & $\begin{array}{l}\text { - Explanar os significados dos números racionais. } \\
\text { - Compreender os números racionais a partir de seus significados, } \\
\text { proposta de Kieren (1988). } \\
\text { - (Re)Conhecer os conhecimentos didático-matemáticos dos professores } \\
\text { quanto aos significados dos números racionais por meio de questionário. }\end{array}$ \\
\hline 3 & $\begin{array}{l}\text { - Os significados dos números } \\
\text { racionais. } \\
\text { - Unidade, comparação, ordenação } \\
\text { e equivalência de números } \\
\text { racionais. } \\
\text { - Resolução de problemas. }\end{array}$ & $\begin{array}{l}\text { - Retomar a compreensão e discussão dos significados dos números } \\
\text { racionais via exercícios dos livros didáticos. } \\
\text { - Compreender a unidade, ordenação e equivalência por meio dos } \\
\text { significados dos números racionais com atividades organizadas em } \\
\text { applets. } \\
\text { - Explorar a metodologia de Resolução de Problemas para o ensino dos } \\
\text { números racionais. }\end{array}$ \\
\hline 4 & $\begin{array}{l}\text { - Material didático: Frac Soma e } \\
\text { jogos didáticos } \\
-\quad 0 \text { conhecimento didático- } \\
\text { matemático do professor }\end{array}$ & $\begin{array}{l}\text { - Compreender o recurso Frac Soma. } \\
\text { - Desenvolver atividades para compreensão dos números racionais por } \\
\text { meio do Frac Soma. } \\
\text { - Compreender o CDM proposto por Godino et al. (2012). } \\
\text { - Identificar e refletir esses conhecimentos na prática do professor em sala } \\
\text { de aula. }\end{array}$ \\
\hline 5 & $\begin{array}{l}\text { - O emprego de jogos em sala de } \\
\text { aula } \\
\text { - Uso de jogos para o ensino de } \\
\text { Matemática: }\end{array}$ & $\begin{array}{l}\text { - Discutir os momentos do jogo pedagógico em sala de aula proposto por } \\
\text { Grando (2000). } \\
\text { - Compreender os recursos: jogo do varal dos números racionais e } \\
\text { bingando com os racionais. }\end{array}$ \\
\hline 6 & $\begin{array}{l}\text { - Construção dos racionais em } \\
\text { documentos curriculares oficiais. }\end{array}$ & $\begin{array}{l}\text { - Identificar e discutir a construção dos números racionais nas grades } \\
\text { curriculares (GC) das escolas do município. } \\
\text { - Conhecer e comparar a construção dos números racionais na BNCC e } \\
\text { GC das escolas municipais. } \\
\text { - Leitura e discutição de entrevistas de alguns estudiosos sobre a BNCC. }\end{array}$ \\
\hline 7 & $\begin{array}{l}\text { - Sequência de ensino baseada nas } \\
\text { habilidades e competências } \\
\text { propostas na BNCC; } \\
\text { - A resolução de problemas como } \\
\text { uma habilidade. }\end{array}$ & $\begin{array}{l}\text { - Apresentar e discutir uma sequência de ensino que explore o tema } \\
\text { números racionais via seus significados. } \\
\text { - Compreender a resolução de problemas e suas etapas; }\end{array}$ \\
\hline 8 & - Criação de problemas. & $\begin{array}{l}\text { - Desenvolver a habilidade de criação de problemas baseado em } \\
\text { Malaspina (2017). }\end{array}$ \\
\hline
\end{tabular}




\begin{tabular}{|l|l|l|}
\hline & & $\begin{array}{l}\text { - Desenvolver atividades para criar problemas por variação ou } \\
\text { elaboração, como também, via histórias em quadrinhos. }\end{array}$ \\
\hline 9 & - Avaliação e Autoavaliação do do & - Avaliar o curso de formação; \\
& curso de formação continuada & - Autoavaliar o seu desempenho (participante) durante o curso de \\
& formação. \\
& - Discutir com o grande grupo as potencialidades e limitações do curso. \\
& - Confraternizar os momentos vividos, os conhecimentos adquiridos, as \\
& pessoas conhecidas... \\
\hline
\end{tabular}

Os instrumentos para a coleta de dados desta investigação foram as observações da formadora durante os encontros, os áudios e vídeos dos encontros e os registros escritos dos professores participantes. Como este trabalho intentou contribuir com a prática de sala de aula do professor de Matemática, optou-se em organizar os registros dos professores por meio da formação e da reflexão do seu trabalho. Desta forma, foi proposta a construção de um portfólio de cada professor durante os encontros do curso. Cada portfólio é único, pois foi construído a partir das dificuldades do professor (ou dos seus alunos), seus encaminhamentos, exemplos ou sequência de ensino.

Além de ter o caráter avaliativo do professor, o portfólio foi proposto como um meio organizador do trabalho pedagógico, pois foi o elo entre o planejamento, a implementação e avaliação durante todo o processo. Neste contexto, cabe destacar, que o ambiente de formação deve propiciar aos professores o seu desenvolvimento profissional, a autonomia intelectual e condições adequadas de trabalho (MURPHY, 1997), possibilitando, assim, parte das produções do portfólio, uma reflexão do professor sobre as possibilidades de uso ou não, com seus alunos (do próprio portfólio ou atividades desenvolvidas).

\subsection{Procedimentos para análise dos dados}

A análise de dados foi realizada por meio do sistema de categorias do CDM que está baseado no modelo do EOS desenvolvido por Godino (2017) e colaboradores. Deste modo, foram analisados os conhecimentos didáticos matemáticos mobilizados pelos professores no curso de formação continuada.

Em Godino et al. (2013) é proposto um guia com componentes e indicadores da idoneidade de programas de formação de professores.

O Quadro 2 apresenta os componentes que devem ser considerados para o planejamento, implementação e avaliação de um processo de formação de professores, chamado de Guia de Avaliação da Idoneidade Didática de Processos de Instrução em Educação Matemática (GVID-IDM). 
Quadro 2: Componentes do GVID-IDM

\begin{tabular}{|c|c|}
\hline $\begin{array}{l}\text { FACETA EPISTÊMICA } \\
\text { Conteúdo didático-matemático, entendido } \\
\text { desde o ponto de vista institucional }\end{array}$ & $\begin{array}{l}\text { Outras facetas implicadas na formação em } \\
\text { educação matemática }\end{array}$ \\
\hline $\begin{array}{l}\text { Conteúdo matemático: problemas, } \\
\text { linguagem, conceito, procedimentos, } \\
\text { proposições, argumentos, conexões. }\end{array}$ & $\begin{array}{l}\text { FACETA COGNITIVA: aprendizagem do } \\
\text { conteúdo didático-matemático pelos } \\
\text { professores. }\end{array}$ \\
\hline $\begin{array}{l}\text { Conteúdo cognitivo: conhecimentos prévios, } \\
\text { adaptaçóes curriculares, aprendizagem do } \\
\text { conteúdo matemático por parte dos alunos. }\end{array}$ & $\begin{array}{l}\text { FACETA AFETIVA: crenças, interesses, } \\
\text { atitudes, emoções dos professores para a } \\
\text { aprendizagem do conteúdo Didático- } \\
\text { matemático. }\end{array}$ \\
\hline $\begin{array}{l}\text { Conteúdo afetivo: interesses, atitudes, } \\
\text { emoções a aprendizagem do conteúdo } \\
\text { matemático dos alunos. }\end{array}$ & $\begin{array}{l}\text { FACETA INTERACIONAL: modos de } \\
\text { interação e discurso no processo de formação }\end{array}$ \\
\hline \multirow{2}{*}{$\begin{array}{l}\text { Conteúdo interacional: modos de interação } \\
\text { e o discurso no processo de ensino e } \\
\text { aprendizagem da matemática. }\end{array}$} & \\
\hline & $\begin{array}{l}\text { FACETA MEDIACIONAL: uso de recursos } \\
\text { tecnológicos no processo de formação de }\end{array}$ \\
\hline \multirow{2}{*}{$\begin{array}{l}\text { Conteúdo mediacional: uso de recursos } \\
\text { tecnológicos no processo de ensino e } \\
\text { aprendizagem da matemática. }\end{array}$} & professores. \\
\hline & FACETA ECOLÓGICA: currículo, \\
\hline $\begin{array}{l}\text { Conteúdo ecológico: currículo, inovação } \\
\text { didática, adaptação sócio-profissional, }\end{array}$ & $\begin{array}{l}\text { inovação didática em formação de } \\
\text { professores, conexões interdisciplinares. }\end{array}$ \\
\hline
\end{tabular}

Fonte: Adaptado de Godino et al (2013, p. 9)

No intuito de contemplar os componentes e indicadores do GVID-IDM, apresenta-se no Quadro 3, como o curso formativo foi planejado. Vale ressaltar, que não foi considerado pontualmente (uma atividade específica) para analisar ou avaliar uma dimensão, mas, as atividades descritas no quadro serviram de parâmetro.

Quadro 3: Atividades desenvolvidas para contemplar os componentes e indicadores do GVID-IDM

\begin{tabular}{|l|l|}
\hline \multicolumn{1}{|c|}{ Dimensões } & \multicolumn{1}{c|}{ Atividades desenvolvidas } \\
\hline Epistêmica & $\begin{array}{l}\text { Compreensão dos números racionais por meio de seus significados e suas diferentes } \\
\text { representações. } \\
\text { Levantamento e discussão sobre dificuldades de ensino e aprendizagem de números racionais. } \\
\text { Análise do livro didático para identificação dos diferentes significados dos racionais. } \\
\text { Compreensão da ordenação, comparação, equivalência e unitarização por meio dos significados dos } \\
\text { racionais. }\end{array}$ \\
\hline Cognitiva & $\begin{array}{l}\text { Superação das dificuldades de ensino e aprendizagem dos números racionais; Conhecimento de } \\
\text { outros métodos de ensino, por exemplo, a resolução de problemas. } \\
\text { Desenvolvimento/elaboração de sequências de ensino sobre os significados e representações dos } \\
\text { números racionais. }\end{array}$ \\
\hline Ecológica & $\begin{array}{l}\text { Estudo da BNCC, das grades curriculares das Escolas e do CDM; Estudo de texto que trate sobre os } \\
\text { documentos curriculares, especificamente, a BNCC - habilidades e competências. }\end{array}$ \\
\hline Mediacional & $\begin{array}{l}\text { A pertinência e adequação de jogos didáticos em sala de aula; Estudo de jogos relacionados ao tema } \\
\text { para potencializar a aprendizagem; Estudo da metodologia de resolução de problemas. }\end{array}$ \\
\hline Afetiva & $\begin{array}{l}\text { Estudo de casos teóricos e particulares dos professores; } \\
\text { Discussão a partir dos anseios dos professores quanto ao tema de estudo e da sua realidade escolar. }\end{array}$ \\
\hline Interacional & $\begin{array}{l}\text { A construção do portfólio individual e sua socialização. } \\
\text { A (re)elaboração e reflexão de ideias por meio do curso. assim como, avaliação do próprio curso e } \\
\text { autoavaliação. }\end{array}$ \\
\hline
\end{tabular}

Fonte: da pesquisa. 


\section{revemop}

\section{Discussão dos resultados}

Nesta seção são apresentados e discutidos os dados via as seis dimensões que balizam um processo de formação continuada de professores na perspectiva do CDM, no intuito de descrever, analisar e avaliar a proposta desenvolvida.

O estudo foi baseado no EOS e no CDM para criar uma trajetória didática para desenvolver cada dimensão, isto é, atividades e situações-problema que pudessem potencializar cada dimensão do processo de formação. Como também, as práticas (matemáticas e didáticas) estão absorvidas em cada dimensão. Vale ressaltar, que os dados não são de um instrumento ou dia de formação (pontuais) para apontar uma dimensão. Em diferentes momentos do curso foram observados, recolhidos indícios/fatos de cada dimensão que orientam essa proposta.

As dimensões, analisadas a seguir, seguem uma sequência de ideias. Primeiramente a epistêmica referente ao conhecimento referencial, a mediacional referente aos meios para mobilizar o conhecimento referencial, a afetiva para considerar os interesses e motivações dos professores ao estudo de casos de referência e particulares envolvendo os números racionais, a ecológica que observa se o conhecimento referencial está de acordo com os documentos curriculares e com as inovações didáticas para o ensino e aprendizagem da Matemática, a cognitiva referente ao conhecimento alcançado pelos professores e a interacional que identifica as interações do processo formativo e investigativo.

\subsection{Dimensão epistêmica}

O critério global para a dimensão epistêmica para um programa de formação de professores é dado pela seleção representativa de conhecimentos didáticos matemáticos de significados institucionais considerados como pertinentes para um ensino idôneo dos números racionais para a etapa de ensino almejada. Além disso, por meio da sondagem de conhecimentos dos professores e pelas atividades iniciais (atividade Quadro 4), organizou-se o curso a fim de desenvolver os componentes e indicadores desta dimensão do processo de formação. 
Quadro 4: Atividade proposta a fim de verificar os conhecimentos prévios dos professores

Leia o enunciado da questão e verifique a solução encontrada por cada aluno. Após, responda os itens abaixo.

Ana deu um meio de suas balas para sua irmã e Jorge deu também a sua irmã um quarto de suas balas. Quem deu mais balas?

A aluna 1 apresentou como resposta a essa situação que Jorge deu mais balas, pois deu o dobro de balas que Ana.

A aluna 2 apresentou como resposta que Ana tinha dado mais balas, pois deu a metade de suas balas e Jorge deu menos da metade de suas balas.

a) No seu entendimento, qual erro a Aluna 1 cometeu? Escreva como tu explicarias à aluna o erro cometido e quais encaminhamentos daria para a solução correta.

b) A resposta da Aluna 2 poderia estar correta, porém sua justificativa não é suficiente para garantir que a resposta esteja correta. O que tu questionarias à aluna para garantir que sua resposta esteja correta?

\section{Fonte: da pesquisa.}

A critério de exemplificação, ilustra-se a atividade do Quadro 4 que buscou explorar 0 conhecimento especializado do professor, isto é, a interação de conhecimentos matemáticos (significados, representações, equivalência, densidade, comparação) e didáticos (diferentes estratégias, encaminhamentos pertinentes, compreensão do pensamento do aluno) que oportunizam a compreensão e solução do problema.

A mobilização do conhecimento matemático dos professores é destacada a partir das soluções sobre grandezas discretas, comparações de frações, fração como um operador, a ideia de todo (unidade) não determinada no enunciado, os tipos de registros adotados (fração, decimal, porcentagem, natural ou figural), procedimentos (parte/todo, operador, razão ou outro). Enfim, que o professor consiga expressar/argumentar de diferentes formas para oportunizar a compreensão dos conceitos abordados na atividade.

A partir da resolução no seu portfólio e socialização com o grupo, foram retomados os objetos matemáticos envolvidos, sendo: uma unidade dividida em duas partes iguais é maior que dividida em quatro partes iguais e, ainda, quanto mais divisões houver, menor será a fatia (fração). Desta forma, opera-se sobre uma mesma quantidade. Se as quantidades não são iguais (o todo), não há como afirmar que uma fração é maior que outra. Via a questão, o aluno pode investigar quais são as possiblidades da quantidade de balas de Ana ou Jorge e quem deu mais. É uma questão simples ao aluno, mas que pode ter diferentes soluções e cria um ambiente investigativo, de busca de estratégias, argumentações e soluçães aos alunos. Neste sentido, um professor afirmou "mostra a atenção que o professor tem ao elaborar uma questão. Essa questão nos colocou numa sinuca".

Ao concluir a retomada das respostas dos professores dos itens (a) e (b) do Quadro 4, observouse que elucidar a questão é dar exemplos concretos (com quantidades de balas). Estes demonstraram 
que sabem como chegar na resposta "correta", ou seja, o conhecimento comum (aquele necessário para responder uma questão) é satisfeito. Entretanto, alguns professores não propuseram indagações para a compreensão da questão ou diferentes estratégias/registros que contempla o conhecimento especializado. Outros professores se prenderam a ideia de que uma fração é maior que a outra, sem compreender a interpretação das frações na situação proposta, logo, pode-se concluir que não há domínio nem do conhecimento comum.

Em se tratando do conhecimento especializado do professor e a pertinência/adequação de recursos explorados como o livro didático, foi proposto uma leitura crítica de como os livros didáticos (aprovados pelo PNLD 2017) apresentam e propõem o estudo dos números racionais no $6^{\circ}$ e $7^{\circ}$ anos do Ensino Fundamental. Desse modo, foi solicitado que os professores descrevessem como o livro emprega os significados dos números racionais nas primeiras atividades (exemplos), se há exercícios que normalmente os estudantes têm dificuldades em resolver e, por fim que o professor indicasse se seguiria a proposta do livro sem alterações.

A proposta de identificar os significados nos livros didáticos teve dois propósitos: um tendo em vista os conteúdos/componentes do GVID-IDM (Quadro 3) para alcançar a dimensão epistêmica, ou seja, modos de interação e discurso no processo de ensino e aprendizagem, o currículo, os recursos, as conexões. E o outro propósito foi analisar os livros didáticos utilizados pelos professores participantes. Optou-se em trabalhar nesse recurso para não ser disruptivo com as práticas já adotadas pelos professores. Tendo em vista que o professor não vai abandonar o livro (que não foi sugerido nessa formação), é necessário que ele consiga identificar e analisar os conhecimentos desenvolvidos nesse recurso didático.

De modo geral os livros didáticos separam no $6^{\circ}$ e $7^{\circ}$ anos 0 estudo dos números fracionários dos decimais. № $7^{\circ}$ ano esses números ainda não são classificados como números racionais. Em geral, os professores adotam o livro didático da escola sem alterações ou alterando alguns exercícios e buscam atividades diferenciadas em outros livros didáticos disponíveis. Os exercícios que causam mais dificuldades aos alunos são aqueles que requerem uma leitura e interpretação (os probleminhas) dificuldades em retirar os dados e determinar o que se pede.

As atividades iniciais para introduzir o estudo de frações trazem, na sua maioria, de forma explícita, os significados das frações: parte/todo, quociente, operador, medida e razão. № $6^{\circ}$ ano os dois primeiros significados e, no $7^{\circ}$ ano, todos os significados (ou a maior parte deles). A questão que fica em aberto é como esses significados são explorados nas atividades (com prevalência de um significado a outros e as concepções fundamentais - como ordenação, densidade, equivalência e comparação). Esses significados não são explorados explicitamente prevalecendo algoritmos/regras). 
Até então, fez-se uso do conhecimento referencial, descrito na literatura sobre o ensino dos números racionais, para desenvolver o conhecimento institucional com os professores de Matemática. Compreendendo que a dimensão epistêmica representa os conhecimentos didáticos matemáticos institucionais pertinentes para um ensino idôneo. Percebeu-se que nenhum significado é novo ao professor, mas a forma de abordá-lo concomitantemente trouxe novas interpretações do número racional (fração) ao processo de ensino.

\subsection{Dimensão mediacional}

A dimensão mediacional foi organizada de forma a contemplar o uso de recursos didáticos (concretos e digitais) de maneira pertinente e oportuna no processo de ensino e aprendizagem de tópicos de Matemática, em específico dos números racionais no Ensino Fundamental - anos finais. Como também, de métodos de ensino que torne $o$ aluno mais ativo na sua aprendizagem.

Partindo do contexto que os professores não tiveram uma sólida formação em recursos educacionais (concretos ou digitais) na sua formação inicial, propõem-se a compreensão das concepções fundamentais dos números racionais: comparação, ordenação, densidade, equivalência, unidade (o todo e partes iguais) e dos significados via applets desenvolvidos no software GeoGebra. Vale ressaltar, que, primeiramente, explorou-se o recurso digital por considerar o recurso que estava mais afastado do professor. Desta maneira, poderia ter maior interesse/motivação para a compreensão desses recursos.

O emprego de recursos durante a formação se alia à ideia de Godino, Batanero e Font (2004), que apontam o uso de recursos tecnológicos como um meio para enriquecer a aprendizagem Matemática, contribuindo para a condução da construção do conhecimento matemático, enfatizando que, em pleno século XXI, o processo de ensino e aprendizagem não deve ficar restrito a quadro e giz ou a práticas que não incluam as tecnologias digitais.

O Quadro 5 ilustra o primeiro applet proposto que explora a comparação (e ordenação) entre duas frações com dois layouts: em forma de reta numérica ou na forma de pizza. 


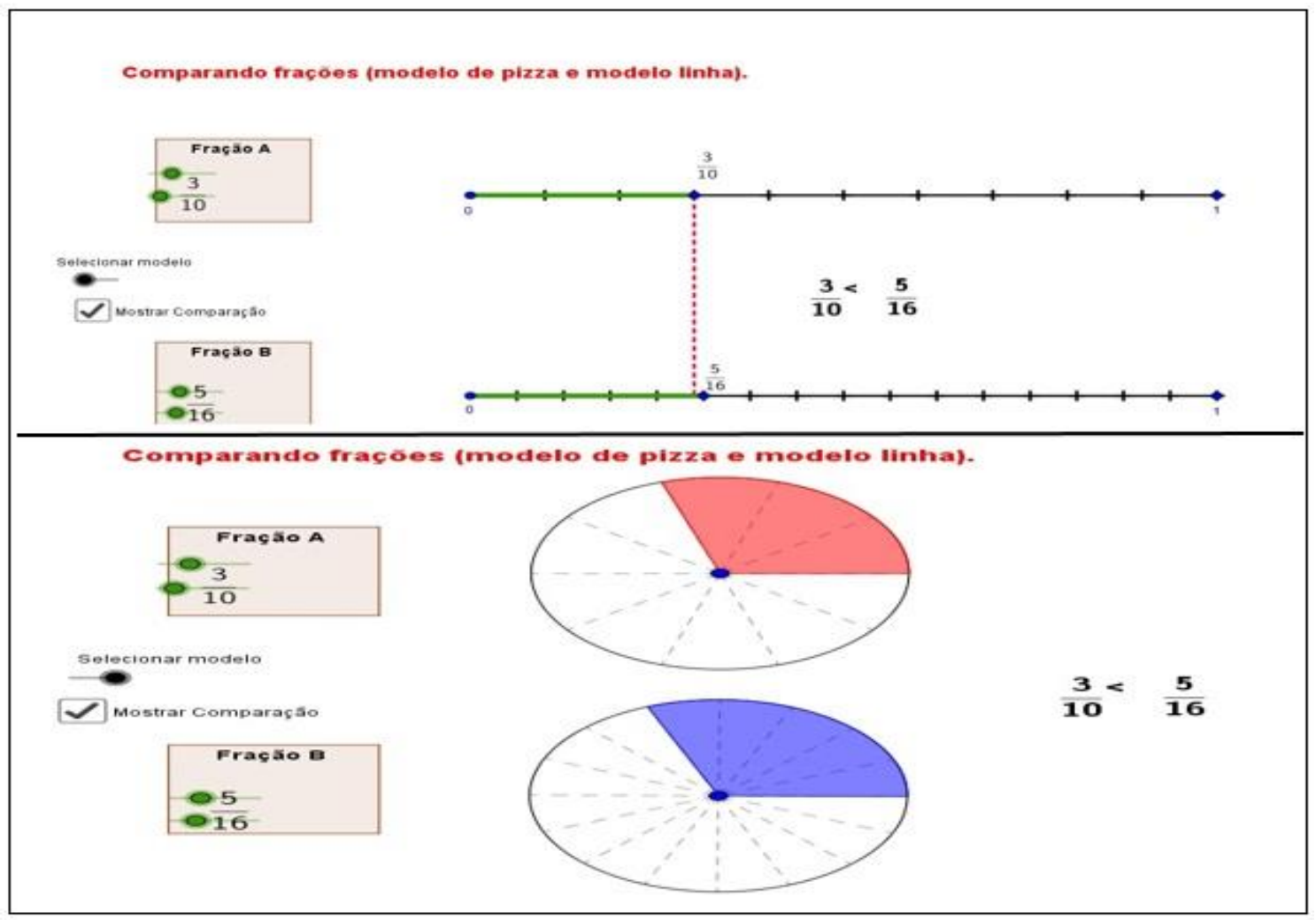

Fonte: disponivel em <https://www.geogebra.org/m/EtanP5kU> Acesso em 29 nov. 2020.

Os professores receberam de forma impressa um roteiro justamente para que fossem manipulando o software para resolverem as atividades. Ressalta-se que a proposta tinha como objetivo que os professores vivenciassem uma atividade e que desenvolvessem a compreensão de um conhecimento matemático (comparação e ordenação de números racionais) por meio de um recurso digital.

Após a realização da atividade, foi discutido o papel do professor ao propor/elaborar uma atividade, pois o applet por si só não garante a aprendizagem e, sim os devidos encaminhamentos do professor. Além disso, foi discutido entre os professores, a importância da tecnologia no nosso meio (cotidiano), entretanto eles são enfáticos em dizer que ela não chegou à escola ainda, seja pela infraestrutura precária da escola ou o não domínio desses recursos digitais por eles próprios.

Na sequência, explorou-se o material concreto Frac Soma 235. Também, foi organizado um roteiro para os professores manipularem as peças. A Figura 2 ilustra a soma de duas frações. 
Figura 2: Representação da soma $\frac{1}{2}+\frac{1}{3}$.

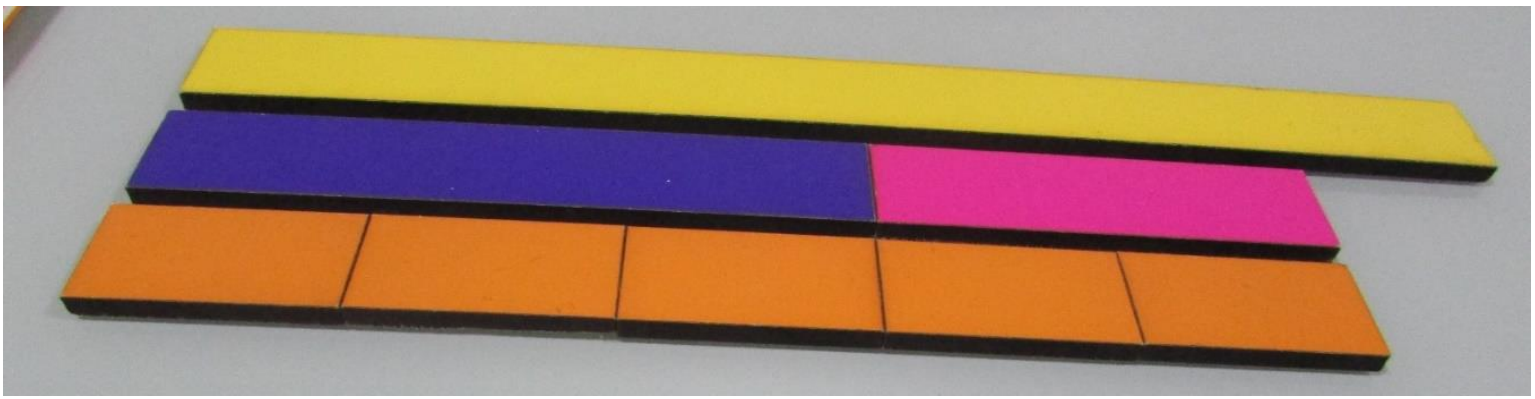

Fonte: da pesquisa.

Um dos jogos desenvolvidos com os professores foi o Jogo do Varal com números racionais (uma corda onde são dispostos os números). Esse jogo é muito conhecido e normalmente substitui/relaciona a reta numérica em livros textos de apoio (livro didático). A atividade foi elaborada para que os professores manipulassem/jogassem e analisassem as potencialidades e limitações do mesmo.

A Figura 3 ilustra o jogo que consiste em o professor determinar um intervalo inicial. Neste caso foi proposto o intervalo [-1,1]. Divide-se a turma em dois grupos e para marcar um número no varal é preciso antes jogar o dado numerado de 1 a 6 . Para os números 1, 2 e 3, o grupo deve marcar um número à esquerda do número escolhido por último. Se forem os números 4, 5 e 6 no dado, o grupo deve marcar um número à direita do número escolhido por último. 0 outro grupo deve jogar o dado e escolher um número no intervalo indicado para marcar no varal. E assim por diante durante 5 rodadas. Se o aluno registra o número certo no varal, o grupo recebe um ponto, caso contrário não marca ponto. Vence o jogo o grupo que pontuar mais.

Figura 3: layout do jogo do varal com números racionais

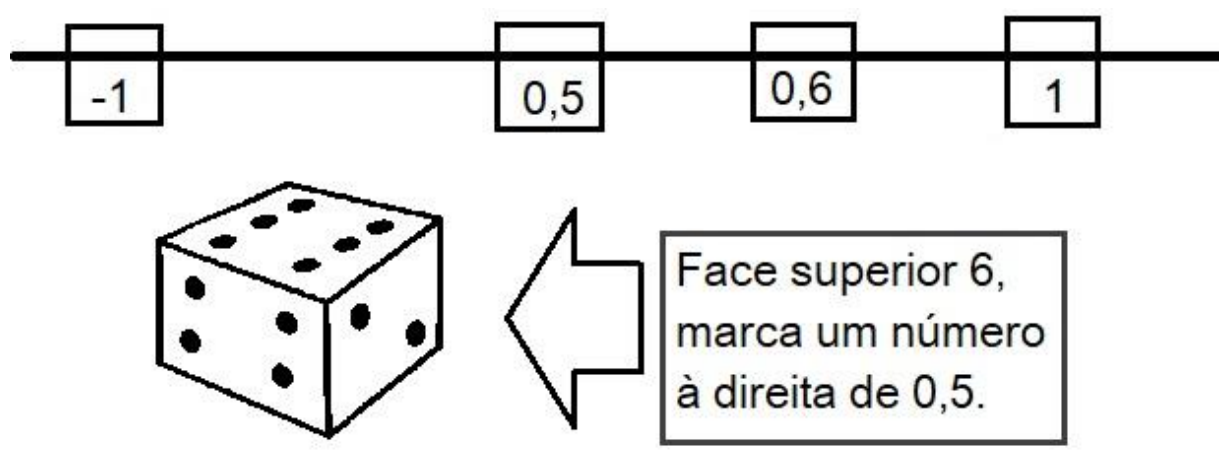

Fonte: da pesquisa

Os professores apresentaram algumas dificuldades ao marcar números menor/maior quando localizados no sentido negativo do varal. Contudo, criou-se um ambiente agradável e oportuno para 


\section{revemop}

mobilizar conhecimentos didáticos matemáticos dos professores (sentiram-se à vontade para sair da cadeira e irem ao quadro para registrar os números no varal e discutir a marcação certa ou errada no quadro).

Godino, Batanero e Font (2004) apontam que os recursos manipulativos desempenham funções representativas que propiciam a compreensão dos significados matemáticos para posterior formulação de conceitos e estruturas matemáticas, podendo, portanto, serem considerados como instrumentos semióticos, servindo de elo entre a realidade e o objeto matemático. Neste contexto foram explorados os jogos durante a formação de professores. Via o jogo supracitado, o aluno pode desenvolver/empregar os tipos de registros de um número racional (transitando nas representações e ampliando sua compreensão de uma quantidade não inteira, por exemplo).

A adequação e pertinência de jogos e applets para mobilizar um conhecimento matemático, no processo de ensino e aprendizagem, foi uma importante demanda proposta no curso de formação. Como também, discutiu-se a necessidade dos encaminhamentos do professor para o emprego desses recursos para potencializar uma aprendizagem aos seus alunos. Os professores colocaram que precisam de um tempo maior para cumprir os objetivos com o emprego de recursos didáticos, mas apontam que há um maior interesse dos alunos e melhor compreensão do objeto de estudo.

\subsection{Dimensão afetiva}

A dimensão afetiva está organizada de forma a contemplar as atitudes, motivações e crenças dos professores que interferem no processo de aprendizagem dos conhecimentos didáticos matemáticos. Como também, por meio dessa dimensão, buscou-se refletir, juntamente com os professores, sobre sua realidade escolar/social e como isso implica na motivação e interesse no processo de ensino e aprendizagem da Matemática.

O primeiro encontro da formação tratava de (re)conhecer os conhecimentos prévios dos professores, possíveis dificuldades e superações. $E$ durante as discussões veio à tona o contexto escolar e as condições árduas de um profissional da educação brasileira nos últimos anos. Os professores se veem numa realidade precária, com duas frentes, que impactam diretamente o seu trabalho no ambiente escolar. Uma delas é a descrença no papel do professor, na escola. A outra frente que impacta diretamente 0 trabalho do professor, dito por eles próprios, é os sucessivos atrasos no pagamento de suas vantagens financeiras. Os atrasos recorrentes nos salários têm causado uma desestrutura não apenas financeira ao professor, como também, emocional interferindo nas suas relações sociais e de 
trabalho. A falta de expectativas de melhorias tem desmotivado o professorado pelo seu próprio trabalho, se refletindo também neste curso de formação continuada.

Diversas vezes percebemos que os professores tinham a necessidade de falar, "colocar para fora" suas angústias sobre as mazelas vivenciadas principalmente no ambiente escolar. Por muitas vezes colocaram que os alunos estão desmotivados, que não querem estudar numa mesmice, porém não estão dispostos a encarar os estudos com mais seriedade e prioridade na vida. Dentro das relações cabíveis, notamos a realidade do aluno como um reflexo das atividades dos professores. Contudo os professores participantes se compreendem como, pelo menos, fazendo o mínimo necessário para "assegurar" a aprendizagem dos seus alunos.

\subsection{Dimensão ecológica}

A dimensão ecológica está organizada de forma a analisar o currículo por meio da Base Nacional Comum Curricular (BNCC, 2017) e a grade curricular do município. Como também, analisar as inovações didáticas obtidas nos cursos de formação de professores, relacionando as tendências da Educação Matemática, o currículo obrigatório e a argumentação crítica por meio do modelo CDM.

A dimensão ecológica desenvolve/aprimora os valores democráticos e o pensamento crítico do professor em suas práticas. Para alcançar essa dimensão, foi proposto esse curso de formação de uma forma dialogada e com trocas de ideias, oportunizando momentos onde limitações/superações fossem discutidas, assim como conflitos semióticos apresentados pelos professores.

Além disso, o ambiente de formação continuada, na perspectiva do CDM, alinhado com a ideia de promover uma maior idoneidade didática no processo de ensino dos números racionais, foi proposto o estudo do próprio GVID-IDM, para abordar o tema inovações didáticas na formação de professores. Visto que, se o professor adquire competência no seu uso pode ter facilitada sua tarefa de planejar, desenvolver e avaliar (GODINO, 2017). Nesse estudo, os professores destacaram as mazelas do ambiente escolar e as dificuldades da utilização do guia.

\subsection{Dimensão cognitiva}

A dimensão cognitiva foi organizada de forma a contemplar o ganho na aprendizagem de conhecimentos didáticos matemáticos pelos professores. Essa dimensão está ligada à superação de dificuldades de ensino do professor e como ele conecta os conhecimentos emergentes durante a formação. 
O curso de formação buscou explorar os conhecimentos pertinentes aos professores de Matemática no processo de ensino, em específico dos números racionais. Em tal processo, a dimensão cognitiva age no sentido de verificar como conhecimentos didático-matemáticos são interpretados e contextualizados na prática pedagógica de cada professor.

A análise da dimensão se deu por meio da elaboração de atividades onde os professores buscaram explorar um objeto matemático em específico a partir do entendimento dos estudos da dimensão epistêmica e, de acordo com a realidade no qual estão inseridos (GODINO; BATANERO; BURGOS; GEA, 2021). Além disso, via a dimensão cognitiva, é possível, ao elaborar problemas e determinar encaminhamentos para a sua compreensão, identificar as técnicas empregadas, como exploram os significados, as representações, a vinculação do número racional a outros objetos matemáticos e a linguagem empregada.

Outra característica, importante e fundamental, em um processo de formação de professores propiciada pela dimensão cognitiva, é a superação de concepções errôneas ou a identificação de dificuldades ao criar ou selecionar atividades. Por exemplo, na análise do processo instrucional de um livro didático, seção frações, do $6^{\circ}$ ou $7^{\circ}$ anos do Ensino Fundamental, os professores puderam ter um novo olhar sobre o livro, apontando quais conhecimentos institucionais não desenvolvidos e possíveis encaminhamentos dos professores para superar as lacunas do livro didático. Nesse procedimento, identificou-se aquisição de conhecimentos pelo professor e superação de fragilidades.

\subsection{Dimensão interacional}

A dimensão interacional foi organizada de forma a contemplar os modos de interação e discurso no processo de formação dos professores, isto é, o desenvolvimento de competências comunicativas durante a formação para o planejamento, desenvolvimento e avaliação do curso.

Todo o curso foi disposto fisicamente por meio do portfólio para cada professor o qual foi o instrumento usado para orientar a proposta. Assim, o portfólio foi muito bem visto/aceito pelos professores. Eles visualizavam, a cada encontro, as atividades já desenvolvidas (caso não tivessem participado de um encontro, o material estava disponível na sua pasta, portfólio).

Além da importância do portfólio para organizar e facilitar as interações formador-professor, professor-professor, formador-recurso e professor-recurso, os professores passaram a se sentir mais próximos da professora formadora e dos colegas e isso permitiu que os relatos, reflexões e angústias fossem compartilhadas/socializadas com o grande grupo. 
Por meio dos componentes e indicadores da dimensão interacional, foi possível abordar se as interações propostas durante o curso potencializaram/facilitaram a participação e compreensão da proposta do estudo. Desse modo, foi desenvolvida a avaliação do curso através de uma dinâmica de placas, onde os professores e formadora puderam retomar pontos, atividades ou discussões para analisa-las e avalia-las (logo também foi um processo formativo). Como também, indicar a autoavaliação do professor ao final curso.

\section{Considerações Finais}

O presente estudo buscou identificar e analisar as contribuições do sistema modular Conhecimentos Didáticos Matemáticos (CDM) em um curso formativo e investigativo com professores de Matemática. A temática do curso versou sobre os conhecimentos dos professores ao ensinar números racionais no Ensino Fundamental.

Foram tomados os componentes e indicadores do Guia de Avaliação da Idoneidade Didática de Processos de Instrução em Educação Matemática (GODINO et al, 2013) para subsidiar a organização do curso e sua análise. A partir do guia, foi possível elaborar e selecionar atividades que promovessem a mobilização de conhecimentos a fim de alcançar um processo de ensino idôneo sobre números racionais.

O curso foi desenvolvido por meio de portfólios construídos individualmente por cada professor. Esses portfólios foram um instrumento potencializador para orientar a proposta da formação, organizar as ideias/pensamentos e as elaborações de atividades. Na troca de experiências e dificuldades do ambiente de sala aula, foi possível observar a reflexão que se agrega/complementa à escrita do portfólio. Como também, o portfólio foi organizado para oportunizar novas experiências aos professores no seu ambiente de sala de aula ao revisitar o material e complementar/aprimorar seu planejamento de ensino e aprendizagem.

As atividades desenvolvidas no curso de formação estavam centradas na elaboração e encaminhamentos das atividades pelo professor, isto é, nos conhecimentos didáticos matemáticos do professor de Matemática, assim como refletir sobre as atividades que desenvolve em sala de aula, porquê as seleciona/organiza e os meios para aplicação. Desta forma, buscou-se trabalhar com os professores atividades que tornassem 0 aluno mais ativo, indagador e argumentativo de suas ideias e soluções.

$O$ ato de refletir sobre a prática de ensino a partir das dimensões do CDM foi marcante durante o curso de formação. Por diversas vezes, ao analisar os conhecimentos epistêmicos e cognitivos ou 
pretendidos e alcançados dado o contexto e meio apropriados é destacado o conhecimento agregado, os encaminhamentos mais pertinentes, as dúvidas fluem naturalmente e o pensamento é revisto.

De forma clara, o GVID-IDM norteou e otimizou as distintas dimensões no ato de ensinar (epistêmica, cognitiva, mediacional, afetiva, interacional e ecológica), isto é, não privilegiou ou excluiu um conhecimento do professor (institucional/cognitivo, comum/especializado, meios/métodos, empatia/interesse, as interações professor/aluno, social/documentos oficiais). Identificaram-se, durante o curso formativo e investigativo, as seguintes contribuições:

- A dimensão epistêmica: o desenvolvimento do conhecimento especializado do professor ao propor a criação ou resolução de problemas. Elaborar problemas é complexo, requer empenho, estudo e conhecimento do que é pertinente ao aluno/professor naquele momento para ser explorado e estimular/desenvolver a aprendizagem via a situação proposta. Dado que havia um distanciamento dos professores à metodologia de Resolução de Problemas, observou-se que os professores precisavam vivenciar, praticar, organizar as ideias/estratégias de ensino e aprendizagem por meio dessa metodologia. Assim, foi proposta uma atividade como se fossem alunos para praticarem e, após, com o olhar de professor, como a atividade foi organizada, os questionamentos e encaminhamentos realizados durante a tarefa, pela formadora.

- A dimensão mediacional: o ressignificado do uso de recursos digitais e concretos para a mobilização do conhecimento matemático. Compreender que um jogo não é uma atividade simplesmente para sair da rotina, mas com potencial de facilitar e estimular a aprendizagem dos alunos.

- A dimensão afetiva: o envolvimento na vida profissional dos professores, ouvir, indicar contrapontos e buscar compreender as situações ou dificuldades foi um desafio durante o curso e colaborou para compreender a realidade vivenciada.

- A dimensão ecológica: a contextualização do entorno social, econômico e regimental (documentos oficiais que balizam a educação) deve balizar o processo de ensino e aprendizagem no ambiente de sala de aula. Como também, aprimorar os valores democráticos e o pensamento crítico do professor em suas práticas e inovações pedagógicas.

- A dimensão cognitiva: como o professor acomoda e supera possíveis dificuldades. A partir desta dimensão é nítida a relação entre a compreensão do conhecimento almejado pelo professor e o alcançado pelo aluno. Por esta dimensão analisou-se, por exemplo, como o professor elabora uma questão, quais meios usa para explicar uma concepção errônea do aluno, quais interpretações faz de tal situação. 
- A dimensão interacional fez fluir as demais dimensões. Foram desenvolvidas, as interações professor-aluno, aluno-aluno e professor-recurso-aluno que promovem o processo de ensino e aprendizagem.

Desse modo, compreende-se que programas de formação continuada de professores de Matemática, com base em pressupostos teóricos definidos e intencionais, como no caso específico do GVID-IDM, mobilizam e aprimoram os conhecimentos didáticos matemáticos dos professores ao ensinar um tópico específico de Matemática.

Em outras palavras, o curso formativo inserido na realidade do professor, com uma temática de estudo apropriada/escolhida, com atividades centradas na elaboração e encaminhamentos do professor com objetivos claros a partir da teoria (articulando de forma coerente e sistêmica os componentes do GVID-IDM), foram balizadores para ampliar os conhecimentos, comum e ampliado, e aprimorar 0 conhecimento especializado do professor de Matemática.

Em específico por meio do GVID-IDM, foi possível descrever, analisar e avaliar os conhecimentos mobilizados e necessários do professor de Matemática para um processo de ensino idôneo dos números racionais, para o Ensino Fundamental. Por meio do guia e articulando as facetas, 0 curso formativo otimizou os conhecimentos, os recursos, as interações, os entornos envolvidos na aprendizagem dos alunos e as motivações para se obter uma maior idoneidade didática.

$\mathrm{Na}$ sequência dos estudos buscar-se-á compreender como e quando os conhecimentos mobilizados durante o curso de formação continuada de professores sustentado pelo CDM, agrega explicitamente à prática de ensino no ambiente de sala de aula. Como também, tal processo de formação pode otimizar e facilitar a aprendizagem dos números racionais no Ensino Fundamental.

\section{Referências}

BALL, Deborah Loewenberg; THAMES, Mark Hoover; PHELPS, Geoffrey. Content knowledge for teaching. What makes it special? Journal of Teacher Education, USA, v. 59, n. 5, p. 389-407, 2008.

BEHR, Merlyn; LESH, Richard; POST, Thomas; SILVER, Edward. Rational number concepts. In LESH, Richard; LANDAU, Marsha. (Eds.). Acquisition of Mathematics Concepts and Processes. New York: Academic Press, 1983. p. 91-125

BORBA, Marcelo Carvalho. A pesquisa qualitativa em Educação Matemática. In: ANAIS DA 27a REUNIÃO ANUAL DA ANPED, Caxambu, MG, p. 21-24, 2004. CD-ROM. Disponível em: http://www.rc.unesp.br/gpimem/downloads/artigos/borba/borba-minicurso_a-pesquisa-qualitativa-emem.pdf. Acesso em 30 abr. 2021 
BREDA, Adriana; FONT, Vicenc; LIMA, Valderez Marina do Rosário. A noção de idoneidade didática e seu uso na formação de professores de matemática. Jornal Internacional de Estudos em Educação Matemática. v.8, n.2; p. 1-41, 2015.

CARPES, Patrícia Pujol Goulart. Conhecimentos didático-matemáticos do professor de Matemática para o ensino dos números racionais. 2019. 265f. Tese (Doutorado em Ensino de Ciências e Matemática), Universidade Franciscana, Santa Maria, Rio Grande do Sul.

FONT, Vicenc; GODINO, Juan. Díaz; GALLARDO, Jesús. The emergence of objects from mathematical practices. Educational Studies in Mathematics, Switzerland, v. 82, p. 97-124, 2013.

GODINO, Juan Díaz:; BATANERO, Carmen. Significado institucional y personal de los objetos matematicos. Recherches en Didactique des Mathématiques, France, v. 14, n.3, p. 325-355, 1994.

GODINO, Juan Díaz. Un enfoque ontologico y semiotico de la cognicion matematica. Recherches en Didactique des Mathématiques, France, v. 22, n. 2/3, p. 237-284, 2002.

GODINO, Juan Díaz; BATANERO, Carmen; FONT, Vicenc. The onto-semiotic approach to research in mathematics education. ZDM. The International Journal on Mathematics Education, USA, v. 39, n. 12, p. 127-135, 2007.

GODINO, Juan Díaz. et al. Componentes e indicadores de idoneidade de programas de formação de professores em educação matemática. REVEMAT. Florianópolis, v. 08, n. 1, p. 46-74, 2013.

GODINO, Juan Díaz Construyendo un sistema modular e inclusivo de herramientas teoricas para la educacion matematica. In: CONTRERAS, J.M. et al (Eds.), Actas del Segundo Congreso International Virtual sobre el Enfoque Ontosemiótico del Conocimiento y la Instrucción Matemática. 2017. Disponible em: http://enfoqueontosemiotico.ugr.es/civeos.html. Acesso em 30 abr. 2021.

GODINO, Juan Díaz; BATANERO, Carmen; BURGOS, María; GEA, María M. Uma perspectiva ontosemiótica dos problemas e métodos de pesquisa em educação matemática. Revemop, v. 3, p. e202107, 21 jun. 2021. DOI: doi.org/10.33532/revemop.e202107

GRANDO, Regina Célia. 0 conhecimento matemático e o uso de jogos na sala de aula. 2000. $239 f$. Tese (Doutorado em Educação) - Universidade Estadual de Campinas, São Paulo, 2000.

IMBERNON, Francisco. Formação docente e profissional: forma-se para a mudança e a incerteza. 9 ed. São Paulo: Editora Cortez. 2017.

LAMON, Susan. Teaching fractions and ratios for understanding: essential content knowledge and instructional strategies for teachers. 2 ed. Mahwah: Lawrence Erlbaum Association. 2006.

MAGINA, Sandra; CAMPOS, Tania. A fração na perspectiva do professor e do aluno dos dois primeiros ciclos do Ensino Fundamental. Boletim de Educação Matemática: Rio Claro, ano 21, n. 31, p. 23-40, 2008.

MALASPINA, Uldorico. La creación de problemas como medio para potenciar la articulación de competencias y conocimientos del profesor de matemáticas (2017). In: CONTRERAS, J. M; ARTEAGA, P.; CAÑADAS, G. R. ; GEA, M. M.; GIAOMONE, B.; LÓPEZ-MARTÍN, M. M. (Eds.), Actas del Segundo Congreso International Virtual sobre el Enfoque Ontosemiótico del Conocimiento y la Instrucción Matemáticos. Disponível em: http://enfoqueontosemiotico.ugr.es/civeos.html. Acesso 07 dez. 2020. 
MALET, Omar; GIACOMONE, Belen; REPETTO, Ana Maria. A Idoneidade didática como ferramenta metodológica: desenvolvimento e contextos de uso. Revemop, v. 3, p. e202110, 22 jun. 2021. DOI: doi.org/10.33532/revemop.e202110

MURPHY, Sandra. Teachers and students: reclaiming assessment via portfolios. In: YANCEY, K.B.; WEISER, I. (ed.). Situating portfolios: four perspectives. Logan, Utah: Utah State University Press, 1997. p. $72-88$.

NÓVOA, António. Os professores e a sua formação. Lisboa: Dom Quixote, 1992.

PINO-FAN, Luis; GODINO, Juan Díaz. Perspectiva ampliada del conocimiento didáctico-matemático del professor. Paradigma, São Paulo, v. XXXVI, n. 1, p. 87- 109, 2015.

SCHOENFELD. Alan; KILPATRICK, Jeremy. Towards a theory of profiency in teaching mathematics. In: TIROSH, D.; WOOD, T.L. (Eds.) Tools and processes in mathematics teacher education. Rotterdam: Sense Publishers. p. 321-354, 2008.

SHULMAN, Lee. Those who understand: Knowledge growth in teaching. Educational Researcher, USA, v.15, n.2, p. 4-14, 1986.

SHULMAN, Lee. Knowledge and teaching: Foundations of the new reform. Harvard Educational Review, USA, v. 57, n.1, p. 1-22, 1987.

SILVA, Maria José Ferreira. Investigando saberes de professores do ensino fundamental com enfoque em números fracionários para a quinta série. 2005. 302f. Tese (Doutorado em Educação Matemática), Pontifícia Universidade Católica de São Paulo, São Paulo. 